\title{
A Triangular Platinum(II) Multi-nuclear Complex with Cytotoxicity Towards Breast Cancer Stem Cells
}

\author{
Arvin Eskandari, ${ }^{[a]}$ Arunangshu Kundu, ${ }^{[b]}$ Sushobhan Ghosh, ${ }^{*[b]}$ Kogularamanan Suntharalingam ${ }^{*[c]}$
}

Dedication ((optional))

\begin{abstract}
The preparation of multi-nuclear metal complexes offers a route to novel anticancer agents and delivery systems. The potency of a novel triangular multi-nuclear complex containing three platinum atoms, Pt-3, towards breast cancer stem cells (CSCs) is reported. The tri-nuclear platinum(II) complex, Pt-3 exhibits selectivity toxicity towards breast CSCs over bulk breast cancer cells and nontumorigenic breast cells. Remarkably, Pt-3 inhibits the formation, size, and viability of mammospheres to a better extent than salinomycin, an established CSC-potent agent, and cisplatin and carboplatin, clinically used platinum drugs. Mechanism of action studies show that Pt-3 effectively enters breast CSCs, penetrates the nucleus, induces genomic DNA damage, and prompts caspasedependent apoptosis. To the best of our knowledge, Pt-3 is the first multi-nuclear platinum complex to selectivity kill breast CSCs over other breast cell types.
\end{abstract}

Platinum(II)-based anticancer drugs, cisplatin, carboplatin, and oxaliplatin, are used worldwide, singularly or in conjunction with other chemotherapeutic agents, to treat various types of cancers. $^{[1]}$ The therapeutic effect of the platinum(II) agents is largely attributed to their ability to covalently bind DNA and distort its structure. ${ }^{[2]}$ This prevents DNA replication and transcription, and trigger programmed cell death. ${ }^{[3]}$ Despite their success, these platinum(II) drugs have significant drawbacks including systemic toxicity and side-effects due to their inability to distinguish between proliferating cancer cells and fast-growing non-tumorigenic cells, acquired or inherent resistance leading to ineffective treatment against several tissue types, and the failure to prevent cancer reoccurrence. ${ }^{[4]}$ The latter is believed to be

[a] A. Eskandari

Department of Chemistry

King's College London

London

SE1 1DB, UK

[b] Dr S. Ghosh, A. Kundu

Department of Chemistry

Gauhati University

Guwahati

Assam, 781014, India

E-mail: sushobhan.iisc@gmail.com

[c] Dr K. Suntharalingam

Department of Chemistry

University of Leicester

Leicester

LE1 7RH, UK

E-mail: k.suntharalingam@leicester.ac.uk

Supporting information for this article is given via a link at the end of the document.((Please delete this text if not appropriate)) related to the existence of cancer stem cells (CSCs), a subpopulation of tumour cells with the ability to differentiate, selfrenew and seed the formation of new tumours. ${ }^{[5]}$ The platinum(II) drugs are unable to effectively remove CSCs (of any tissue type) at their clinically administered doses. ${ }^{[6]}$ This is primarily due to elevated levels of DNA repair-linked effectors (such as BRCA1, ATR, ATM, and Chk1) and platinum-related drug efflux pumps (such as ATP-binding cassette transporters) in CSCs. ${ }^{[7]}$ Indeed, several independent in vitro and in vivo studies have shown that cisplatin, carboplatin, and oxaliplatin, all enrich rather than deplete, CSCs in heterogeneous tumour populations. ${ }^{[8]}$ Therefore there is a clear need for the development of novel platinum agents that can remove both bulk cancer cells and CSCs at clinically relevant concentrations.

Multi-nuclear inorganic structures with well-defined geometry and size can be readily prepared. ${ }^{[9]}$ The application of such macromolecular entities in cancer research has increased over the last two decades. ${ }^{[10]} \mathrm{A}$ triple helicate with two iron(II) ions and three bisazopyridine ligands was shown bind to threeway duplex DNA junctions and exhibit reasonable activity against a range of bulk cancer cell lines. ${ }^{[11]}$ Independently, the same helicate with two nickel(II) ions, instead of two iron(II) ions, was reported to bind tightly to G-quadruplex DNA and preferentially reduce breast CSC growth over bulk breast cancer cells. ${ }^{[12]}$ Structurally similar di-ruthenium(II) double-stranded complexes displayed up to 100 -fold greater potency (submicromolar range) for bulk breast cancer cells than cisplatin whereas an analogous di-ruthenium(II) triple-stranded helicate exhibited significantly lower activity (micromolar range) ${ }^{[13]}$ More recently, di-iron(II) helicate-like architectures, prepared via diastereoselective self-assembly, were shown to kill bulk colon cancer cells lacking p53 (a vital tumour suppressor) in the nanomolar range, with nearly 1000 -fold greater potency than non-cancerous retinal pigment epithelial cells. ${ }^{[14]}$ Remarkably, cytotoxicity studies with di-ruthenium(II) double-stranded helicate and mesocate complexes showed that the former favorably killed bulk colon cancer cells lacking p53 and the latter killed bulk colon cancer cells possessing p53. ${ }^{[15]}$

Multi-nuclear platinum(II) complexes have been widely studied as potential anticancer agents and drug delivery vehicles. $^{[1 \mathrm{1c}, 16]}$ Notably, the tri-nuclear complex, [transdiamminechloroplatinum(II)][ $\mu$-trans-

diamminebis(hexanediamine)platinum(II)] nitrate (BBR3464) was shown to covalently bind DNA, induce atypical DNA lesions that evade DNA repair, and prompt cell death in cisplatinresistant cell lines. ${ }^{[17]}$ Despite clinical trials suggesting partial response in non-small cell lung cancer and advanced ovarian cancer patients, follow-up studies have not been reported. ${ }^{[18]}$ The non-coordinating analogues of BBR3464, TriplatinNC and TriplatinNC-A exhibit strong DNA binding affinity and bulk cancer 
cell potency. ${ }^{[19]}$ A hexanuclear platinum(II) assembly containing six platinum(II) centres and four 2,4,6-tris(4-pyridyl)-1,3,5triazine ligands exhibited promising in vitro potency against a panel of bulk cancer cell lines. ${ }^{[20]}$ The same platinum(II) cage was also successfully deployed as a delivery vehicle for platinum(IV) prodrugs into certain bulk cancer cells. ${ }^{[21]}$ Despite the growing interest in studying the anticancer properties of multi-nuclear inorganic structures, none of the platinum(II) multinuclear complexes reported to date have been challenged with CSCs. Here we report a triangle-shaped, tri-nuclear platinum(II) complex with breast CSC potency and selectivity (over bulk breast cancer cells and non-tumorigenic breast cells). This is, as far as we are aware, the first study to investigate the anti-CSC properties of a platinum(II) multi-nuclear complex.

The tri-platinum(II) complex, Pt-3 was prepared as outlined in Scheme S1. Specifically, Pt-3 was prepared by reacting equimolar amounts of $\mathrm{Pt}(1,1$ bis(diphenylphosphino)ethylene) $\left(\mathrm{OSO}_{2} \mathrm{CF}_{3}\right)_{2} \quad$ (Pt-1a), benzotriazole, and sodium methoxide in DMF at $80^{\circ} \mathrm{C}$ for $3 \mathrm{~h}$. Methanol was added to the resultant solution to remove impurities as precipitates, and diethyl ether was triturated into the filtrate to yield pure Pt-3 as a white solid. Purified Pt-3 was fully characterised by ${ }^{1} \mathrm{H}$ NMR and infrared spectroscopy, highresolution ESI mass spectrometry, and elemental analysis (see ESI, Figure S1-4). Single crystals (colourless blocks) of Pt-3 suitable for X-ray diffraction studies were obtained by slow diffusion of diethyl ether into a methanol:DMF (9:1) solution of Pt-3 (CCDC 1906805, Figure 1 and Table S1). Selected bond distances and bond angles data are presented in Table S2. The structure consists of three platinum(II) centres, each coordinated to two phosphorous atoms belonging to 1,1bis(diphenylphosphino)ethylene and two nitrogen atoms from two separate benzotriazole ligands. The complex, Pt-3 is tricationic and crystallizes with three triflate counter anions and one molecule of DMF. The average P-Pt-P bite angle is $85.22^{\circ}$ and the average $\mathrm{N}-\mathrm{Pt}-\mathrm{N}$ bite angle is $85.43^{\circ}$. This shows that each platinum(II) centre adopts a pseudo square-planar geometry. The average Pt-N (2.08 $\AA$ ) and Pt-P $(2.24 \AA)$ bond distances are consistent with bond parameter for related platinum(II) complexes. ${ }^{[22]}$ The adjacent Pt-Pt distances vary from 5.882 to $5.918 \AA$, and the $\mathrm{Pt}(2)-\operatorname{Pt}(1)-\operatorname{Pt}(3)$ angle = $59.71^{\circ}, \mathrm{Pt}(2)-\mathrm{Pt}(3)-\mathrm{Pt}(1)$ angle $=59.98^{\circ}$, and $\mathrm{Pt}(1)-\operatorname{Pt}(2)-\operatorname{Pt}(3)$ angle $=60.31$. Therefore the three platinum atoms are arranged in an equilateral triangular orientation relative to each other.

By reacting benzotriazole and sodium methoxide with two equivalence of

$\operatorname{Pt}(1,1-$ bis(diphenylphosphino)ethylene) $\left(\mathrm{OSO}_{2} \mathrm{CF}_{3}\right) \mathrm{Cl}(\mathbf{P t}-\mathbf{1 b})$ in $\mathrm{DMF}$ at $80{ }^{\circ} \mathrm{C}$ for $3 \mathrm{~h}$, the di-nuclear platinum(II) complex, Pt-2 was isolated (Scheme S2). The di-nuclear platinum(II) complex, Pt-2 was fully characterised by standard spectroscopic and analytical methods (see ESI, Figure S3, S5). Single crystals (colourless) of Pt-2 suitable for X-ray diffraction studies were obtained by slow diffusion of diethyl ether into a DCM:DMF (9:1) solution of Pt-2 (CCDC 1906803, Figure 2 and Table S1). Selected bond distances and bond angles data are presented in Table S3. The structure consists of two platinum(II) centres, each coordinated to two phosphorous atoms belonging to 1,1bis(diphenylphosphino)ethylene, one nitrogen atom from benzotriazole, and one chloride ligand. Akin to Pt-3, the
platinum(II) centres in Pt-2 adopt a pseudo square-planar geometry, with the average P-Pt-P bite angle being $85.65^{\circ}$ and the average $\mathrm{N}-\mathrm{Pt}-\mathrm{Cl}$ bite angle being $89.95^{\circ}$. The dihedral angle between the $\mathrm{P}(2) \mathrm{P}(1) \mathrm{Pt}(1) \mathrm{Cl}(1) \mathrm{N}(1)$ and $\mathrm{P}(3) \mathrm{P}(4) \mathrm{Pt}(2) \mathrm{Cl}(2) \mathrm{N}(3)$ is $130.38^{\circ}$. The average $\mathrm{Pt}-\mathrm{N}(2.10 \AA)$, $\mathrm{Pt}-\mathrm{P}(2.24 \AA)$, and $\mathrm{Pt}-\mathrm{Cl}$ $(2.35 \AA$ ) bond distances are consistent with bond parameter for related platinum(II) complexes. ${ }^{[2]}$

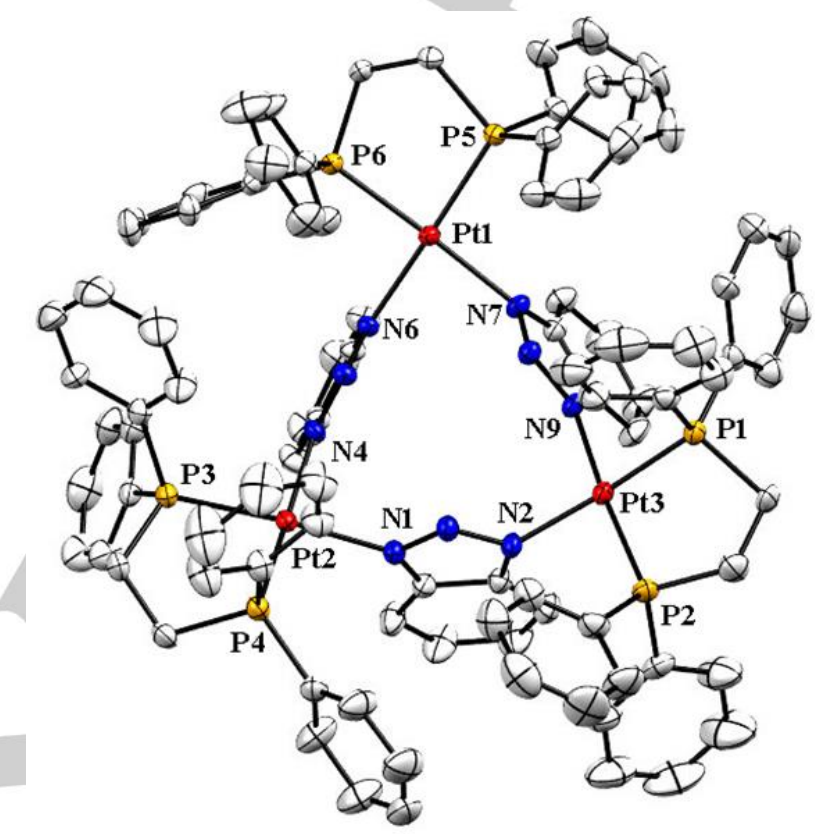

Figure 1. X-ray structure of the triangular, tri-nuclear platinum(II) complex, $\mathbf{P t}$ 3 comprising of three $\mathrm{Pt}(1,1-\mathrm{bis}($ diphenylphosphino)ethylene) moieties and three deprotonated benzotriazole ligands. Ellipsoids are shown at $30 \%$ probability, $\mathrm{C}$ in grey, $\mathrm{N}$ in dark blue, $\mathrm{P}$ in yellow, and $\mathrm{Pt}$ in red. $\mathrm{H}$ atoms, cocrystallizing triflate counter anions, and solvent molecules have been omitted for clarity.

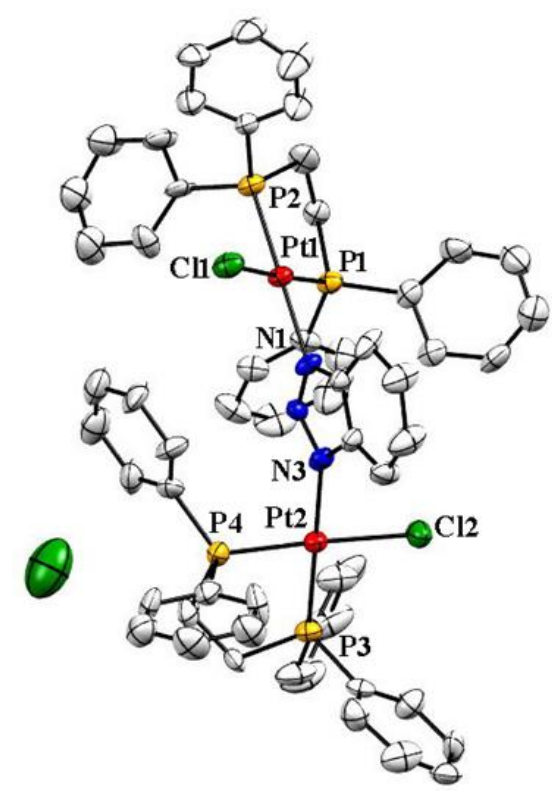

Figure 2. X-ray structure of the di-nuclear platinum(II) complex, Pt-2 comprising of two $\mathrm{Pt}(1,1$-bis(diphenylphosphino)ethylene) moieties and one deprotonated benzotriazole ligand. Ellipsoids are shown at $30 \%$ probability, C in grey, $\mathrm{N}$ in dark blue, $\mathrm{P}$ in yellow, $\mathrm{Cl}$ in green, and $\mathrm{Pt}$ in red. $\mathrm{H}$ atoms have been omitted for clarity. 
The cytotoxicity of the tri-nuclear platinum(II) complex, Pt-3, along with its mono-nuclear (Pt-1a) and di-nuclear (Pt-2) analogues, towards breast CSC-enriched HMLER-shEcad cells and CSC-depleted HMLER cells was determined using the MTT assay. The $\mathrm{IC}_{50}$ values were determined from dose-response curves (Figure S6-8) and are summarised in Table 1. The trinuclear platinum(II) complex, Pt-3 exhibited micromolar potency towards both cell lines, comparable to salinomycin (an established breast CSC-potent agent). ${ }^{[23]}$ Notably, Pt-3 exhibited 2-fold greater potency $(p<0.01, \mathrm{n}=18)$ for HMLER-shEcad cells over HMLER cells (Figure S8). The mono- and di-nuclear complexes, Pt-1a and Pt-2, also exhibit micromolar potency towards bulk breast cancer cells and breast CSCs, but do not display CSC selectivity (Figure S6-7). This suggests that the multi-nuclear structure of Pt-3 contributes to CSC-selective potency. As expected the anticancer platinum(II) drugs, cisplatin and carboplatin, exhibited preferential potency for bulk breast cancer cells over breast CSCs (Table 1 and Figure S9-10). As a measure of therapeutic potential, the cytotoxicity of Pt-3 towards normal human epithelial breast MCF710A cells was determined. The complex, Pt-3 was 2-fold less potent toward MCF710A cells $\left(\mathrm{IC}_{50}\right.$ value $=2.59 \pm 0.12 \mu \mathrm{M}$, Figure S11) than HMLER-shEcad cells, indicating selective toxicity for breast CSCs over nontumorigenic breast cells.

Table 1. $\mathrm{IC}_{50}$ values of the platinum(II) complexes, Pt-1a, Pt-2, Pt-3, cisplatin, carboplatin, and salinomycin against HMLER cells, HMLER-shEcad cells, and HMLER-shEcad mammospheres.

\begin{tabular}{cccc}
\hline Compound & $\begin{array}{c}\text { HMLER } \\
\mathrm{IC}_{50}[\mu \mathrm{M}]^{[\mathrm{a}]}\end{array}$ & $\begin{array}{c}\text { HMLER-shEcad } \\
\mathrm{IC}_{50}[\mu \mathrm{M}]^{[\mathrm{a}]}\end{array}$ & $\begin{array}{c}\text { Mammosphere } \\
\mathrm{IC}_{50}[\mu \mathrm{M}]^{[\mathrm{b}]}\end{array}$ \\
\hline Pt-1a & $5.01 \pm 0.03$ & $7.01 \pm 0.06$ & $14.50 \pm 0.91$ \\
Pt-2 & $2.59 \pm 0.09$ & $2.35 \pm 0.01$ & $16.00 \pm 0.56$ \\
Pt-3 & $2.24 \pm 0.01$ & $1.26 \pm 0.03$ & $4.55 \pm 0.02$ \\
cisplatin & $2.57 \pm 0.02$ & $5.65 \pm 0.30$ & $13.50 \pm 2.34$ \\
carboplatin & $66.11 \pm 0.50$ & $72.59 \pm 0.09$ & $18.06 \pm 0.40$ \\
salinomycin & & \\
& $11.43 \pm 0.42$ & $4.23 \pm 0.35$ & $18.50 \pm 1.50$ \\
\hline
\end{tabular}

[a] Determined after $72 \mathrm{~h}$ incubation (mean of three independent experiments \pm SD). [b] Determined after 5 days incubation (mean of three independent experiments \pm SD). [c] Reported in references $23 a$ and 24 .

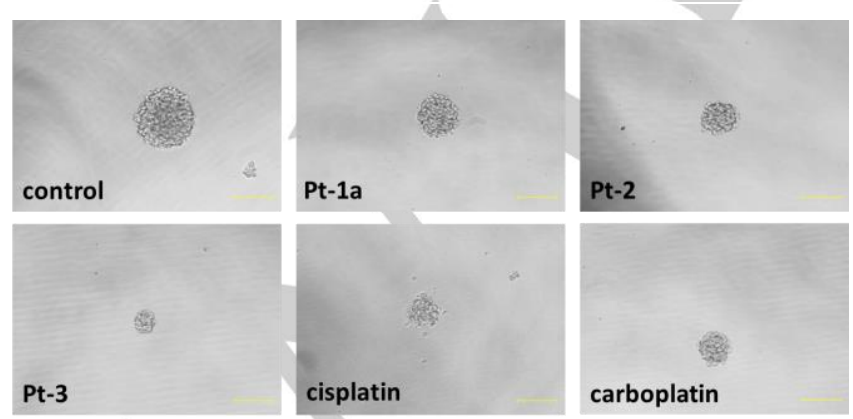

Figure 3. Representative bright-field images $(x$ 20) of HMLER-shEcad spheroids in the absence and presence of Pt-1a, Pt-2, Pt-3, cisplatin, and carboplatin at their respective $\mathrm{IC}_{20}$ values (5 days incubation).
Breast CSCs grown in serum-free media, under lowattachment conditions form three-dimensional, tumour-like structures called mammospheres. To reliably gauge the in vivo CSC potential of the platinum(II) complexes, Pt-1a, Pt-2, and Pt3, the mammosphere formation assay was performed. Treatment of single cell suspensions of HMLER-shEcad cells with the platinum(II) complexes, Pt-1a, Pt-2, and Pt-3 $\left(\mathrm{IC}_{20}\right.$ value for 5 days) noticeably reduced the number and size of mammospheres formed (Figure 3 and S12). The greatest inhibitory effect was observed for Pt-3 and it was comparable or better than the effect observed for salinomycin treatment $\left(\mathrm{IC}_{20}\right.$ value for 5 days) (Figure 3 and S12-13). Addition of cisplatin and carboplatin (at their $\mathrm{IC}_{20}$ value for 5 days) also reduced the number and size of mammospheres formed, albeit to a lesser level than Pt-3 (Figure 3 and S12). To determine the effect of Pt1a, Pt-2, and Pt-3 on mammosphere viability, the colorimetric resazurin-based reagent, TOX8 was used. All of the platinum(II) complexes displayed micromolar potency (Table 1 and Figure 4). Notably, the tri-nuclear platinum(II) complex Pt-3, displayed $\geq 3$ fold greater potency for mammospheres than the mono- and dinuclear complexes, Pt-1a, Pt-2, and cisplatin, and >4-fold greater potency than salinomycin ${ }^{[24]}$ and carboplatin (Table 1 and Figure 4).

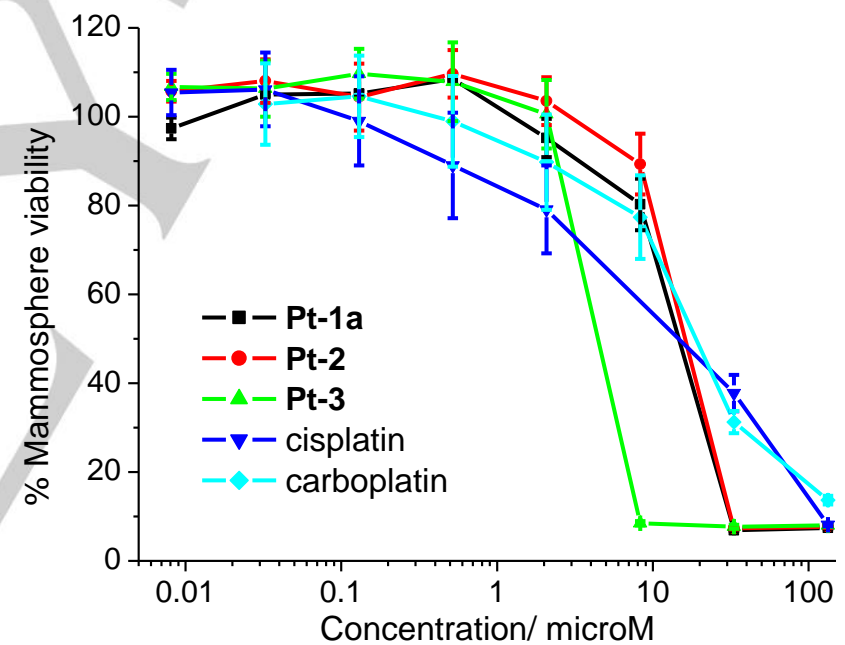

Figure 4. Representative dose-response curves for the treatment of HMLERshEcad spheroids with Pt-1a, Pt-2, Pt-3, cisplatin, and carboplatin. The concentration of treated Pt-1a, Pt-2, Pt-3, cisplatin, and carboplatin was based on Pt concentration.

To shed light on the mechanism of CSC toxicity of the platinum(II) complexes further cell-based studies were conducted. Cellular uptake studies were carried out to determine breast CSC permeability. HMLER-shEcad cells were treated with Pt-2, Pt-3, and cisplatin at a non-lethal dose (2 $\mu \mathrm{M}$ for $24 \mathrm{~h})$ and the internalized platinum content was determined by inductively coupled plasma mass spectrometry (ICP-MS). As depicted in Figure 5, the tri- and di-nuclear complexes, Pt-3 and Pt-2 (727.88 \pm 13.25 and $579.47 \pm 10.37 \mathrm{ppb}$ of $\mathrm{Pt} / \mathrm{million}$ cells respectively) were taken up more readily than cisplatin (41.01 \pm $0.62 \mathrm{ppb}$ of $\mathrm{Pt} /$ million cells). A clear correlation between HMLER-shEcad cellular uptake and lipophilicity (LogP values) of Pt-2, Pt-3, and cisplatin was observed (Table S4). The amount of Pt-2, Pt-3, and cisplatin entering breast CSC nuclei, and thus gaining access to genomic DNA, was also determined (Figure 5). 
A reasonably large amount of internalized Pt-3 was detected in the nucleus (15\%). Relatively lower levels of internalized Pt-2 (8\%) and cisplatin (7\%) were recorded in breast CSC nuclei, suggesting that Pt-3 has the greatest potential to damage genomic DNA. Taken together, the cellular uptake data suggests that Pt-3-mediated CSC death could be related to a genomic DNA-dependent pathway.

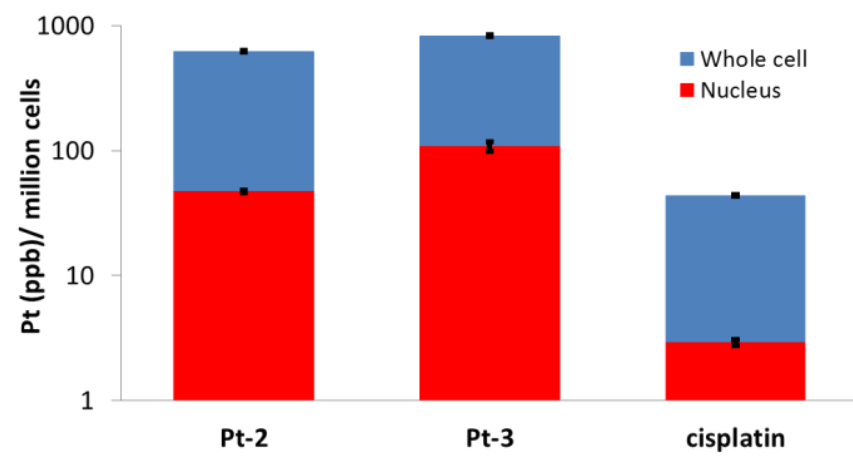

Figure 5. Platinum content in whole cell and nucleus fractions isolated from HMLER-shEcad cells treated with Pt-2, Pt-3, or cisplatin $(2 \mu \mathrm{M}$ for $24 \mathrm{~h})$. The $y$-axis is given the logarithmic scale. Error bars = SD. The concentration of treated Pt-2, Pt-3, and cisplatin was based on Pt concentration.

As the tri-nuclear platinum(II) complex, Pt-3 was shown to enter breast CSC nuclei, its potential to damage genomic DNA was probed by monitoring the expression of biomarkers related to the DNA damage pathway using immunoblotting methods. HMLER-shEcad cells incubated with Pt-3 $(0.5-1 \mu \mathrm{M}$ for $72 \mathrm{~h})$ displayed a marked increase in the expression of the phosphorylated forms of $\mathrm{H} 2 \mathrm{AX}$ and $\mathrm{CHK} 2$, indicative of DNA damage (Figure S14). ${ }^{[25]}$ Traditional anticancer platinum(II) complexes such as cisplatin bind covalently to genomic DNA. ${ }^{[36]}$ As the platinum(II) centres in Pt-3 are bound to strongly coordinating ligands and given the reasonable stability of Pt-3 in biologically relevant conditions (PBS, PBS with cellular reductant, and cell media) (Figure S15-17), the multi-nuclear complex is likely to, mainly, interact with genomic DNA in a non-covalent manner. ${ }^{1} \mathrm{H}$ NMR spectroscopy and ESI mass spectrometry studies were also performed to confirm the stability of the trinuclear platinum(II) complex, Pt-3 in partially aqueous solution (see ESI, Figure S18-19).

To compare the ability of Pt-3, Pt-2, and cisplatin to covalently bind DNA, the ct-DNA precipitation assay was carried out (see ESI). The amount of platinum on ct-DNA increased in the following order Pt-3 $(16.63 \pm 2.52 \mathrm{mg} / \mathrm{L})<\mathrm{Pt}-2(138.13 \pm$ $3.77 \mathrm{mg} / \mathrm{L})<$ cisplatin $(212.16 \pm 2.49 \mathrm{mg} / \mathrm{L})$. This is consistent with the presence of labile $\mathrm{Pt}-\mathrm{Cl}$ bonds in cisplatin and Pt-2 and not in Pt-3. To determine the non-covalent binding affinity and mode of Pt-3 to DNA, ethidium bromide (a strong intercalator) and DAPI (a strong minor groove binder) displacement studies were carried out. Upon incremental addition of Pt-3 $(0-35 \mu \mathrm{M})$ to a solution of ct-DNA $(20 \mu \mathrm{M})$ and ethidium bromide $(1 \mu \mathrm{M})$, the emission associated to the ethidium bromide-DNA complex (originating from the intercalation of ethidium bromide between DNA base pairs) markedly decreased (Figure S20). Upon incremental addition of Pt-3 $(0-35 \mu \mathrm{M})$ to a solution of ct-DNA $(20 \mu \mathrm{M})$ and DAPI $(1 \mu \mathrm{M})$, the emission associated to the DAPIDNA complex (originating from the binding of DAPI to the minor groove) decreased to a similar extent (Figure S21). Indeed the ethidium bromide quenching constant $\left(\mathrm{K}_{\mathrm{q}}=7.4 \pm 0.1 \times 10^{4} \mathrm{M}^{-1}\right)$ was similar to the DAPI quenching constant $\left(\mathrm{K}_{\mathrm{q}}=7.6 \pm 0.2 \times 10^{4}\right.$ $\left.\mathrm{M}^{-1}\right)$. Control studies with Pt-1a and Pt-2 (both $0-35 \mu \mathrm{M}$ ), revealed that Pt-2 displaced ethidium bromide and DAPI from ctDNA to a greater level than Pt-1a (Figure S20-21 and Table S5). This suggests that the intercalative and groove binding ability of
Pt-3 is facilitated by the Pt(1,1-bis(diphenylphosphino)ethylene) unit bound to benzotriazole rather than the $\mathrm{Pt}(1,1$ bis(diphenylphosphino)ethylene) unit alone. Collectively this suggests that Pt-3 binds to DNA non-covalently, and this probably triggers a DNA damage response.

Unrepaired DNA lesions can lead to apoptosis. ${ }^{[26]}$ HMLERshEcad cells exposed to Pt-3 (0.5-2 $\mu \mathrm{M}$ for $72 \mathrm{~h}$ ) displayed markedly higher levels of cleaved caspase 3 and 7 compared to untreated cells (Figure 6A), characteristic of caspase-dependent apoptosis. Cytotoxicity studies in the presence of z-VAD-FMK (5 $\mu \mathrm{M})$, a peptide-based caspase-dependent apoptosis inhibitor showed that the potency of Pt-3 towards HMLER-shEcad cells decreased significantly $\left(p<0.05, I_{50}\right.$ value $\left.=2.20 \pm 0.05 \mu \mathrm{M}\right)$ (Figure 6B). This confirms that Pt-3 induces caspase-dependent CSC death. As expected the potency of cisplatin, a well-known apoptosis-inducer, towards HMLER-shEcad cells decreased significantly $\left(p<0.05, \mathrm{IC}_{50}\right.$ value $\left.=10.21 \pm 0.78 \mu \mathrm{M}\right)$ in the presence of z-VAD-FMK $(5 \mu \mathrm{M})$ (Figure S22). Interestingly the potency of Pt-1 and Pt-2 towards HMLER-shEcad cells was not significantly altered $\left(\mathrm{IC}_{50}\right.$ value of Pt-1 $=9.14 \pm 1.09 \mu \mathrm{M}$ and $\mathrm{IC}_{50}$ value of Pt-2 $=2.65 \pm 0.31 \mu \mathrm{M}$ ) in the presence of $z$-VAD-FMK $(5 \mu \mathrm{M})$, suggesting that these platinum(II) complexes act via a non-apoptotic mechanism (Figure S23-24). Overall the cellular studies show that Pt-3 can enter the nucleus and induces genomic DNA damage, which ultimately leads apoptotic CSC death.
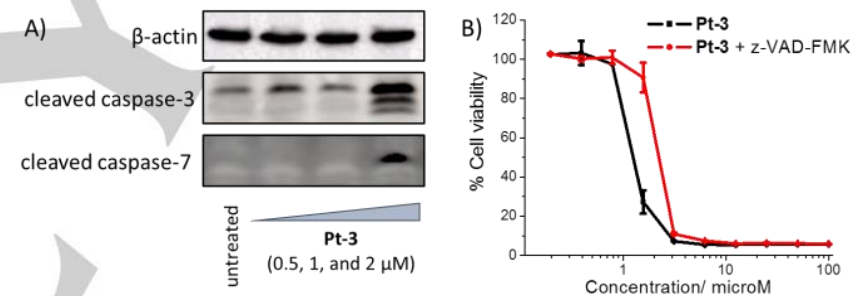

Figure 6. (A) Immunoblotting analysis of proteins related to the caspasedependent apoptosis pathway. Protein expression in HMLER-shEcad cells following treatment with Pt-3 $(0.5,1$, and $2 \mu \mathrm{M}$ for $72 \mathrm{~h})$. (B) Representative dose-response curves of Pt-3 against HMLER-shEcad cells in the absence and presence of $z$-VAD-FMK $(5 \mu \mathrm{M})$ after $72 \mathrm{~h}$ incubation. The concentration of treated Pt-3 was based on Pt concentration.

In summary we show that a triangle-shaped platinum(II) metallacycle, Pt-3, exhibits impressive potency and selectivity toward breast CSCs in vitro. Strikingly, Pt-3 exhibits significantly greater breast CSC potency than salinomycin, cisplatin, and carboplatin in monolayer and three-dimensional cell cultures. The tri-nuclear complex, Pt-3 induces breast CSC apoptosis by entering breast CSCs in relatively large quantities, bypassing the nuclear membrane, and inducing genomic DNA damage. As far as we are aware, this is first report of a platinum-based multinuclear complex with promising anti-CSC activity. Our findings reinforce the therapeutic potential of multi-nuclear agents and more specifically provides the basis for their development as breast CSC-selective agents.

\section{Acknowledgements}

K.S. was supported by a Leverhulme Early Career Fellowship (ECF-2014-178). S.G. is funded by a UGC start-up grant (F.4$5 / 2006, B S R)$ and the Newton Alumni Fund. A.E. is supported 
by a KCL studentship. Thanks to Dr. Biswajit Bhattacharya (BAM Federal Institute for Materials Research and Testing) for useful discussions and suggestions with respect to the X-ray crystallography studies. We are grateful to Prof. Robert Weinberg (Whitehead Institute, MIT) for providing the cell lines used in this study.

Keywords: platinum $\bullet$ cancer $\cdot$ DNA damage $\cdot$ multi-nuclear metal complexes• antitumor agents

[1] a) S. P. Fricker, Dalton Trans. 2007, 4903-4917; b) L. Kelland, Nat. Rev. Cancer 2007, 7, 573-584; c) T. C. Johnstone, K. Suntharalingam, S. J. Lippard, Chem. Rev. 2016, 116, 3436-3486; d) N. J. Wheate, S. Walker, G. E. Craig, R. Oun, Dalton Trans. 2010, 39, 8113-8127.

[2] a) Y. Jung, S. J. Lippard, Chem. Rev. 2007, 107, 1387-1407; b) B. Lippert, Verlag Helvetica Chimica Acta ; Wiley-VCH, Zürich Weinheim ; New York, 1999.

[3] a) R. C. Todd, S. J. Lippard, Metallomics 2009, 1, 280-291; b)D. Wang, S. J. Lippard, Nat. Rev. Drug Discov. 2005, 4, 307-320.

[4] a) V. Brabec, J. Kasparkova, Drug Resist. Updat. 2005, 8, 131-146; b) S. R. McWhinney, R. M. Goldberg, H. L. McLeod, Mol. Cancer Ther. 2009, 8 , 10-16; c) Z. H. Siddik, Oncogene 2003, 22, 7265-7279.

[5] a) L. V. Nguyen, R. Vanner, P. Dirks, C. J. Eaves, Nat. Rev. Cancer 2012 12, 133-143; b) V. Plaks, N. Kong, Z. Werb, Cell Stem Cell 2015, 16, 225 238.

[6] F. Tomao, A. Papa, L. Rossi, M. Strudel, P. Vici, G. Lo Russo, S. Tomao, J. Exp. Clin. Cancer Res. 2013, 32, 48.

[7] C. Gasch, B. Ffrench, J. J. O'Leary, M. F. Gallagher, Mol. Cancer 2017 $16,43$.

[8] a) L. Wang, X. Liu, Y. Ren, J. Zhang, J. Chen, W. Zhou, W. Guo, X. Wang, H. Chen, M. Li, X. Yuan, X. Zhang, J. Yang, C. Wu, Cell Death Dis. 2017 8, e2746; b) S. S. Li, J. Ma, A. S. T. Wong, J. Gynecol. Oncol. 2018, 29 e32; c) B. Thakur, P. Ray, J. Exp. Clin. Cancer Res. 2017, 36, 164; d) K Suntharalingam, W. Lin, T. C. Johnstone, P. M. Bruno, Y. R. Zheng, M. T. Hemann, S J Lippard, J Am Chem Soc. 2014, 136, 14413-14416; e) C. Saygin, A. Wiechert, P. Thiagarajan, V. Rao, J. Hale, M. Hitomi, A. DiFeo, J. Lathia, O. Reizes, J. Clin. Oncol. 2016, 34, e17098-e17098; f) G Bertolini, L. Roz, P. Perego, M. Tortoreto, E. Fontanella, L. Gatti, G. Pratesi, A. Fabbri, F. Andriani, S. Tinelli, E. Roz, R. Caserini, S. Lo Vullo, T. Camerini, L. Mariani, D. Delia, E. Calabro, U. Pastorino, G. Sozzi, Proc Natl. Acad. Sci. U. S. A. 2009, 106, 16281-16286.

[9] T. R. Cook, P. J. Stang, Chem. Rev. 2015, 115, 7001-7045

[10] a) T. R. Cook, V. Vajpayee, M. H. Lee, P. J. Stang, K. W. Chi, Acc. Chem Res. 2013, 46, 2464-2474; b) M. J. Hannon, Chem. Soc. Rev. 2007, 36, 280-295; c) B. Therrien, Top. Curr. Chem. 2012, 319, 35-55; d) R. A Kaner, P. Scott, Future Med. Chem. 2015, 7, 1-4; e) J. E. M. Lewis, E. L. Gavey, S. A. Cameron, J. D. Crowley, Chem. Sci. 2012, 3, 778-784; f) S K. Samanta, D. Moncelet, V. Briken, L. Isaacs, J. Am. Chem. Soc. 2016 138, 14488-14496; g) S. K. Samanta, J. Quigley, B. Vinciguerra, V. Briken, L. Isaacs, J. Am. Chem. Soc. 2017, 139, 9066-9074; h) F. Kaiser, A Schmidt, W. Heydenreuter, P. J. Altmann, A. Casini, S. A. Sieber, F. E. Kühn, Eur. J. Inorg. Chem. 2016, 2016, 5189-5196.

[11] a) A. Oleksi, A. G. Blanco, R. Boer, I. Usón, J. Aymamí, A. Rodger, M. J. Hannon, M. Coll, Angew. Chem. Int. Ed. 2006, 45, 1227-1231; b) A. C. G. Hotze, N. J. Hodges, R. E. Hayden, C. Sanchez-Cano, C. Paines, N. Male, M.-K. Tse, C. M. Bunce, J. K. Chipman, M. J. Hannon, Chem. Biol. 2008 $15,1258-1267$.

[12] H. Qin, C. Zhao, Y. Sun, J. Ren, X. Qu, J. Am. Chem. Soc. 2017, 139 16201-16209.

[13] a) A. C. Hotze, B. M. Kariuki, M. J. Hannon, Angew. Chem. Int. Ed. 2006 45, 4839-4842; b) G. I. Pascu, A. C. G. Hotze, C. Sanchez-Cano, B. M. Kariuki, M. J. Hannon, Angew. Chem. Int. Ed. 2007, 46, 4374-4378.

[14] a) R. A. Kaner, S. J. Allison, A. D. Faulkner, R. M. Phillips, D. I. Roper, S. L. Shepherd, D. H. Simpson, N. R. Waterfield, P. Scott, Chem. Sci. 2016 7, 951-958; b) A. D. Faulkner, R. A. Kaner, Q. M. A. Abdallah, G. Clarkson, D. J. Fox, P. Gurnani, S. E. Howson, R. M. Phillips, D. I. Roper, D. H. Simpson, P. Scott, Nat. Chem. 2014, 6, 797.

[15] S. J. Allison, D. Cooke, F. S. Davidson, P. I. P. Elliott, R. A. Faulkner, H. B. S. Griffiths, O. J. Harper, O. Hussain, P. J. Owen-Lynch, R. M. Phillips, C R. Rice, S. L. Shepherd, R. T. Wheelhouse, Angew. Chem. Int. Ed. 2018 57, 9799-9804.

[16] a) N. J. Wheate, J. G. Collins, Curr. Med. Chem. Anticancer Agents 2005 5, 267-279; b) N. Wheate, Coord. Chem. Rev. 2003, 241, 133-145.

[17]a) V. Brabec, J. Kasparkova, O. Vrana, O. Novakova, J. W. Cox, Y. Qu, N. Farrell, Biochemistry 1999, 38,6781-6790; b) P. Perego, C. Caserini, L. Gatti, N. Carenini, S. Romanelli, R. Supino, D. Colangelo, I. Viano, R.
Leone, S. Spinelli, G. Pezzoni, C. Manzotti, N. Farrell, F. Zunino, Mol .Pharmacol. 1999, 55, 528-534.

[18] a) A. H. Calvert, H. Thomas, N. Colombo, M. Gore, H. Earl, L. Sena, G. Camboni, P. Liati, C. Sessa, Eur. J. Cancer 2001, 37, S260; b) G. Scagliotti, S. Novello, L. Crinò, F. De Marinis, M. Tonato, C. Noberasco, G. Selvaggi, F. Massoni, B. Gatti, G. Camboni, Lung Cancer 2003, 41, S223.

[19] a) $Y$ Qu A Harris, A. Hegmans, A Petz P Kabolizadeh, H Penazova, N. Farrell, J. Inorg. Biochem. 2004, 98, 1591-1598; b) S. Komeda, T. Moulaei, M. Chikuma, A. Odani, R. Kipping, N. P. Farrell, L. D. Williams Nucleic Acids Res. 2011, 39, 325-336; c) A. L. Harris, X. Yang, A Hegmans, L. Povirk, J. J. Ryan, L. Kelland, N. P. Farrell, Inorg. Chem. 2005, 44, 9598-9600.

[20] Y. R. Zheng, K. Suntharalingam, P. M. Bruno, W. Lin, W. Wang, M. T. Hemann, S. J. Lippard, Inorganica Chim. Acta 2016, 452, 125-129.

[21] Y.-R. Zheng, K. Suntharalingam, T. C. Johnstone, S. J. Lippard, Chem. Sci. 2015, 6, 1189-1193.

[22] a) M. Schweiger, S. R. Seidel, A. M. Arif, P. J. Stang, Angew. Chem. Int Ed. 2001, 40, 3467-3469; b) T. Weilandt, R. W. Troff, H. Saxell, K Rissanen, C. A. Schalley, Inorg. Chem. 2008, 47, 7588-7598.

[23] a) J. N. Boodram, I. J. McGregor, P. M. Bruno, P. B. Cressey, M. T. Hemann, K. Suntharalingam, Angew. Chem. Int. Ed. 2016, 55, 28452850 ; b) P. B. Gupta, T. T. Onder, G. Jiang, K. Tao, C. Kuperwasser, R. A. Weinberg, E. S. Lander, Cell 2009, 138, 645-659.

[24] C. Lu, K. Laws, A. Eskandari, K. Suntharalingam, Dalton Trans. 2017, 46, 12785-12789.

[25] a) E. P. Rogakou, D. R. Pilch, A. H. Orr, V. S. Ivanova, W. M. Bonner, J. Biol. Chem. 1998, 273, 5858-5868; b) J. Y. Ahn, J. K. Schwarz, H. Piwnica-Worms, C. E. Canman, Cancer Res. 2000, 60, 5934-5936.

[26] W. P. Roos, A. D. Thomas, B. Kaina, Nat. Rev. Cancer 2016, 16, 20-33. 
Entry for the Table of Contents (Please choose one layout)

\section{COMMUNICATION}
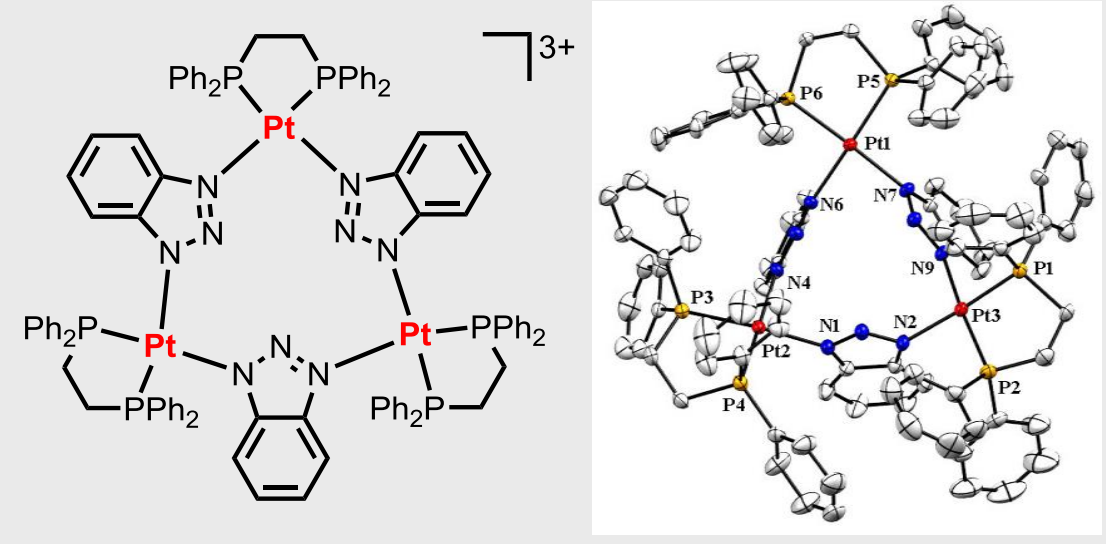

Arvin Eskandari, Arunangshu Kundu, Sushobhan Ghosh, * Kogularamanan Suntharalingam*

\section{Page No. - Page No.}

Title

Killing cancer stem cells with platinum triangles: $A$ multi-nuclear triangle complex with platinum(II) atoms at each corner is reported, and its breast cancer stem cell (CSC) potency and mechanism of cytotoxicity is described in detail. The triangle complex kills breast CSCs by inducing genomic DNA damage and triggering caspasedependent apoptosis. 